\title{
Cardiac Tamponade following Transbronchial Needle Aspiration
}

\author{
Andreas Gross ${ }^{\mathrm{a}} \quad$ Andreas Henri Diacon ${ }^{\mathrm{b}}$ \\ a Department of Internal Medicine, Pulmonary Medicine, Kantonsspital Baden, Baden, Switzerland; \\ ${ }^{b}$ Departments of Medicine and Biomedical Sciences, Tygerberg Academic Hospital and Stellenbosch University, \\ Cape Town, South Africa
}

\section{For editorial comment see p. 1}

\section{Established Facts}

- Bronchoscopic transbronchial needle aspiration is generally a safe procedure.

- The pericardium can be reached with transbronchial needle aspiration.

\section{Novel Insights}

- Cardiac tamponade is a rare but serious complication of transbronchial needle aspiration.

- Careful target evaluation is needed before attempting distal pretracheal aspiration.

\section{Key Words}

Cardiac tamponade $\cdot$ Bronchoscopy $\cdot$ Transbronchial needle aspiration

\begin{abstract}
Bronchoscopic transbronchial fine needle aspiration of the mediastinum is generally known as a safe procedure. Complications such as pneumothorax, pneumomediastinum, major bronchial haemorrhage and significant bleeding after a major vessel puncture are rare events. We report the first case, to our knowledge, of life-threatening cardiac tamponade following transbronchial fine needle aspiration in precarinal location.

Copyright $\odot 2011$ S. Karger AG, Basel
\end{abstract}

\section{Introduction}

Transbronchial needle aspiration (TBNA) of the mediastinum is established as an important diagnostic technique for mediastinal lymph node staging in lung cancer [1]. Even though TBNA is considered to bear a low risk, severe complications can still occur. We report the first case of a life-threatening cardiac tamponade following TBNA of a suspected distal pretracheal lymph node.

\section{Case Description}

A 65-year-old male, healthy non-smoker was referred for a left-sided pulmonary nodule of unknown origin. All routine investigations were normal. The nodule was located in the apical segment of the left lower lobe, abutted the pleura and measured 


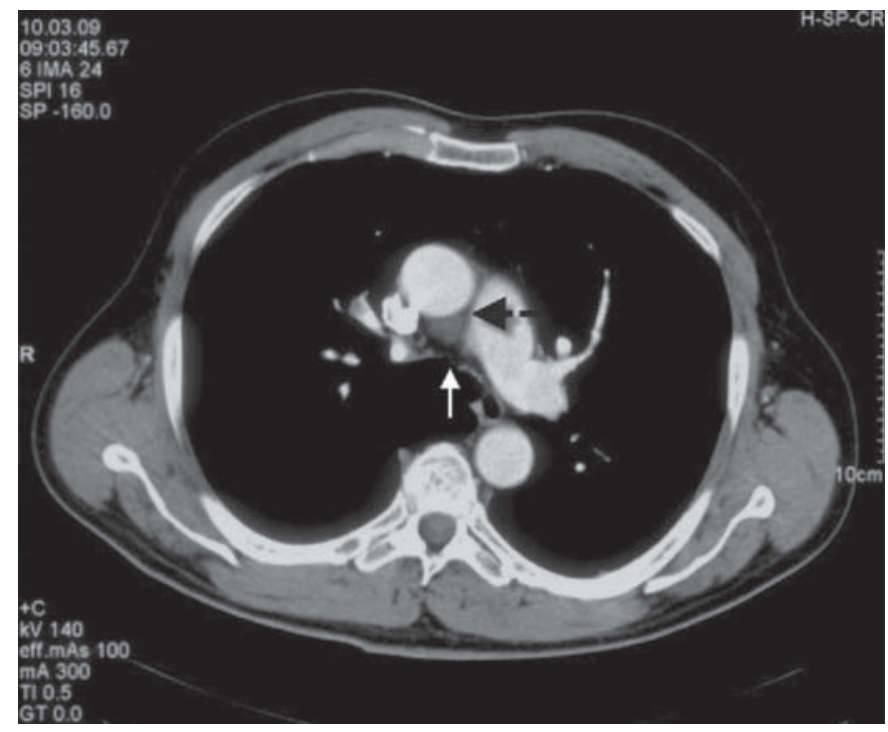

Fig. 1. Pre-intervention chest CT. The white arrow represents the planned direction of puncture, the black arrow the precarinal lymph node target.

$20 \times 25 \times 25 \mathrm{~mm}$. A single enlarged mediastinal lymph node measuring $19 \times 14 \times 10 \mathrm{~mm}$ was described in precarinal location on contrasted computed tomography (CT) (fig. 1). Flexible diagnostic bronchoscopy was performed by an experienced bronchoscopist under conscious sedation with midazolam and dihydrocodein, with routine safety precautions including supplemental oxygen by nasal cannula, intravenous access, and continuous non-invasive monitoring of heart rate, ECG, blood pressure and oxygen saturation by pulse oximetry. Endoscopic inspection was unremarkable. TBNA was conducted with a 21-gauge needle of 15 mm length (Excelon ${ }^{\circledR}$; Boston Scientific) introduced between the second and third most distal cartilage ring of the trachea in anterior direction. Blood was aspirated with the first needle pass but no bleeding into the bronchial system occurred following retraction of the needle. Shortly after needle retraction the patient complained of intense back pain, and within few minutes blood pressure dropped gradually to $80 / 40 \mathrm{~mm} \mathrm{Hg}$ and oxygen saturation fell to $80 \%$. The heart rate remained within normal limits. Breath sounds could be heard on both sides of the chest and no neck vein distension was noticed. An emergency CT scan ruled out haematothorax and massive pulmonary embolus, but identified a large pericardial fluid collection (fig. 2). A catheter inserted under sonographic guidance drained $400 \mathrm{ml}$ of blood from the pericardium but the patient remained hypotensive. Upon emergency surgery via substernal laparotomy the pericardium was fenestrated and $750 \mathrm{ml}$ of partially coagulated blood evacuated with immediate full recovery of vital signs. No recurrent bleeding occurred and the patient left the hospital 10 days later, albeit with a still undiagnosed pulmonary nodule. Subsequent positron emission tomography (PET) scanning was negative for enhancing mediastinal lymph nodes. Surgical exploration including mediastinoscopy revealed bronchogenic adenocarcinoma without lymph node involvement (stage IB, pT2N0M0).

Cardiac Tamponade following TBNA

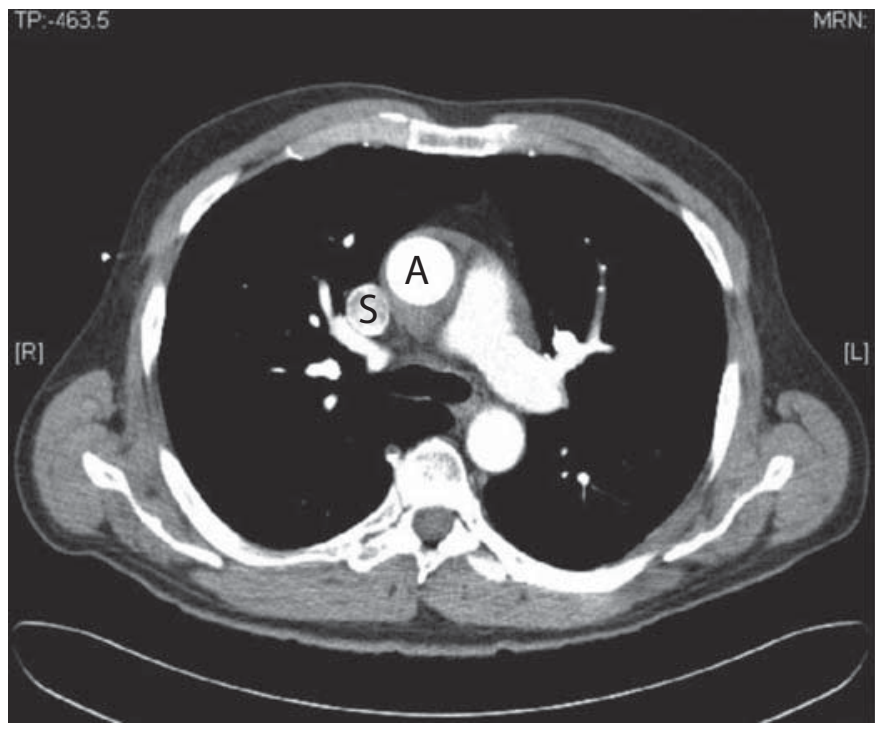

Fig. 2. Post-intervention chest CT. Note the increased volume surrounding the aorta $(\mathrm{A})$ and the enlarged diameter of the superior vena cava $(S)$.

\section{Discussion}

To the best of our knowledge the case presented here is the first report of cardiac tamponade as a life-threatening complication of a transbronchial fine needle aspiration. Bronchoscopic TBNA of the mediastinum is described as a safe procedure even in patients with pulmonary hypertension [2] and when larger bore 19-gauge needles are used [3]. Major complications including pneumothorax, pneumomediastinum and major bronchial haemorrhage occur with an estimated frequency of only $0.3 \%$ [4]. Cases of symptomatic, non-fatal haemomediastinum [5-7] and chylothorax [8] have been reported following TBNA.

Significant bleeding rarely occurs even after a major vessel puncture [9], which is most probably due to instant compression of the punctured vessel by surrounding structures in the mediastinum. In the present case the haemorrhage was most likely caused by transpericardial puncture of a major vessel such as the intrapericardial portion of the ascending aorta or of the left atrium (fig. 3). Even in the absence of visible haemorrhage into the bronchial system regional compression failed to stop the haemorrhage in this case because blood could run off and collect in the pericardium.

Pericardial complications are rare following medical interventions. Cases of cardiac tamponade following the placement of central lines mainly in children [10] and fol- 


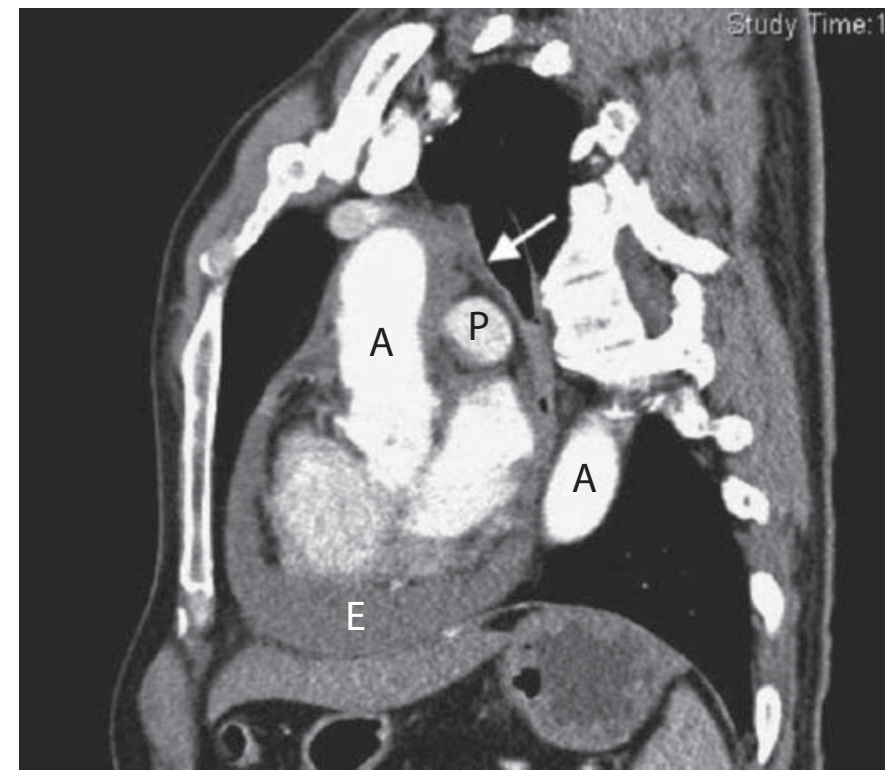

Fig. 3. Post-intervention chest CT sagittal reconstruction rotated in the axis of the heart. The white arrow shows the site and direction of the TBNA. $\mathrm{A}=$ Aorta; $\mathrm{P}=$ left pulmonary artery; $\mathrm{E}=$ pericardial effusion.

lowing percutaneous CT-guided fine needle aspiration of the mediastinum [11] have been reported. The fact that the pericardium can be reached with TBNA is well known and has been used for therapeutic pericardial puncture [12]. Drainage was achieved in predominantly posterior pericardial effusions that could not be reached percutaneously, using TBNA through the anterior wall of the distal trachea and the left lower lobe bronchus. Cases of a bacterial pericarditis have been observed in association with bronchoscopic transtracheal fine needle puncture of the mediastinum $[13,14]$.

There are multiple factors that could have contributed to the event reported here. Firstly, the absence of actual lymph node tissue at the puncture site would enable the needle to penetrate directly into adjacent structures. In the present case, a pericardial fold was most likely misinterpreted as a lymph node. CT reconstructions (fig. 3) indicate that the suspected pretracheal lymph node was in fact identical with the posterior portion of a superior aortic recess of the pericardium. The prevalence of such 'high-riding' superior pericardial recesses posterior of the aorta has been investigated in a large number of individuals with thin-section CT $[15,16]$. Posterior superior aortic recesses were found in up to $44.7 \%$ of people, and about $1 \%$ of such recesses seem able to mimic lymph nodes in shape and size. This means that the classic ra-

diological criterion to delineate the pericardial sinus from the heart and great vessels by acute-angle demarcation is not always accurate. A high density on CT scan and PET positivity in case of malignant disease can be further clues to differentiate between recess and lymph node. Secondly, needle length could be a factor. The length of commercially available 21 - to 22-gauge transbronchial cytology aspiration needles varies within 13$15 \mathrm{~mm}$. Such devices are routinely used with high safety and efficacy [17]. The needle length used in the present case was able to cover the distance from the tracheal wall to the posterior layer of the pericardial fold on reconstructed CT scans. Thirdly, it could be speculated that the incident could have been prevented with endobronchial ultrasound (EBUS). However, lymph nodes close to leading landmarks such as the main carina are easily targeted via conventional TBNA, which is the faster procedure and has a comparable yield [18]. EBUS could probably have distinguished between lymph node tissue and a fluid-filled pericardial fold. In such cases it can be expected that complications will be minimized with EBUS-TBNA when compared to conventional TBNA. However, case reports have related convex probe EBUS-TBNA to infectious complications and the much greater penetration depth of convex probe EBUS-TBNA (up to $36 \mathrm{~mm}$ ) could potentially increase the complication risk of TBNA when handled without the necessary circumspection [14].

This case report demonstrates that the bronchoscopist should be aware of the rare complication of a cardiac tamponade following TBNA at precarinal locations. Careful evaluation of the CT scan with regard to the position, shape and density of structures possibly representing pericardial recesses is important for the safety of TBNA. Even though TBNA is performed according to the commonly accepted recommendations and is considered to bear a low risk, life-threatening situations can occur.

References
1 Medford AR, Bennett JA, Free CM, Agrawal S: Mediastinal staging procedures in lung cancer: EBUS, TBNA and mediastinoscopy. Curr Opin Pulm Med 2009;15:334-342.

2 Diaz-Guzman E, Vadi S, Minai OA, Gildea TR, Mehta AC: Safety of diagnostic bronchoscopy in patients with pulmonary hypertension. Respiration 2009;77:292-297.

- 3 Stratakos G, Porfyridis I, Papas V, Kandaraki $\mathrm{C}$, Zisis $\mathrm{C}$, Mariatou V, et al: Exclusive diagnostic contribution of the histology specimens obtained by 19-gauge transbronchial aspiration needle in suspected malignant intrathoracic lymphadenopathy. Chest 2008;133:131-136. 
4 Holty JE, Kuschner WG, Gould MK: Accuracy of transbronchial needle aspiration for mediastinal staging of non-small cell lung cancer: a meta-analysis. Thorax 2005;60: 949-955.

5 Kucera RF, Wolfe GK, Perry ME: Hemomediastinum after transbronchial needle aspiration. Chest 1986;90:466.

6 Lazzari Agli L, Trisolini R, Burzi M, Patelli $\mathrm{M}$ : Mediastinal hematoma following transbronchial needle aspiration. Chest 2002;122: 1106-1107.

7 Talebian M, Recanatini A, Zuccatosta L, Gasparini S: Hemomediastinum as a consequence of transbronchial needle aspiration. Journal of Bronchology 2004;11:178-181.

$>8$ Mobeireek A, Quraishi E, Zeitouni M, AlDalaan A: Chylothorax complicating transbronchial fine needle aspiration: a care report. Journal of Bronchology 2007;14:127128.
$>9$ Ernst A, Silvestri GA, Johnstone D: Interventional pulmonary procedures: guidelines from the American College of Chest Physicians. Chest 2003;123:1693-1717.

10 Askegard-Giesmann JR, Caniano DA, Kenney BD: Rare but serious complications of central line insertion. Semin Pediatr Surg 2009; 18:73-83.

11 Man A, Schwarz Y, Greif J: Case report: cardiac tamponade following fine needle aspiration (FNA) of a mediastinal mass. Clin Radiol 1998;53:151-152.

12 Ceron L, Manzato M, Mazzaro F, Bellavere F: A new diagnostic and therapeutic approach to pericardial effusion: transbronchial needle aspiration. Chest 2003;123:17531758.

13 Epstein SK, Winslow CJ, Brecher SM, Faling LJ: Polymicrobial bacterial pericarditis after transbronchial needle aspiration. Case re port with an investigation on the risk of bacterial contamination during fiberoptic bronchoscopy. Am Rev Respir Dis 1992;146:523525 .
14 Haas AR: Infectious complications from full extension endobronchial ultrasound transbronchial needle aspiration. Eur Respir J 2009;33:935-938.

15 Kodama F, Fultz PJ, Wandtke JC: Comparing thin-section and thick-section CT of pericardial sinuses and recesses. AJR Am J Roentgenol 2003;181:1101-1108.

16 Basile A, Bisceglie P, Giulietti G, Calcara G, Figuera M, Mundo E, et al: Prevalence of 'high-riding' superior pericardial recesses on thin-section 16-MDCT scans. Eur J Radiol 2006;59:265-269.

17 Fernandez-Villar A, Leiro V, Blanco M, Represas C, Botana M, Gonzalez A, et al: Efficacy and safety of the eXcelon transbronchial aspiration needle in mediastinal lymph node enlargement: a case-control study. Respiration 2007;74:208-213.

18 Herth F, Becker HD, Ernst A: Conventional vs endobronchial ultrasound-guided transbronchial needle aspiration: a randomized trial. Chest 2004;125:322-325. 